\title{
A percepção de servidores públicos a respeito da prática dos princípios LIMPE: um estudo na Universidade de Brasília.
}

\section{The perception of public servants about the practice of the principles LIMPE: a study at the University of Brasilia.}

\author{
Alisson Assis de Lima ${ }^{1}$ \\ Luiz Honorato da Silva Júnior ${ }^{2}$
}

\begin{abstract}
RESUMO
O objetivo deste trabalho é buscar evidências sobre a percepção dos servidores públicos da Universidade de Brasília a respeito da prática dos princípios constitucionais da Administração Pública explícitos no caput do artigo 37 da Constituição Federal. Foram propostos indicadores para avaliar a autopercepção e a percepção sobre a prática dos princípios no ambiente de trabalho e aplicados 893 questionários de pesquisa junto aos servidores da Universidade. Os resultados sugerem que a autopercepção de cumprimento é sempre maior que a percepção que se tem de tais princípios no ambiente de trabalho do respondente. Verifica-se que características como idade e tempo trabalhado na Instituição parecem não se relacionar significativamente para a percepção de tal prática. Por outro lado, características como gênero, cargo e o fato de exercer uma função de gestão se relacionam com uma maior ou menor percepção de cumprimento. Os resultados deste trabalho podem contribuir com uma autocrítica institucional e em adoção de medidas que aperfeiçoem a observância de tais princípios.
\end{abstract}

PALAVRAS-CHAVE: Princípios da administração pública; Administração Pública; UnB; Servidores Públicos; LIMPE.

\section{ABSTRACT}

The aim of this paper is to seek evidence on the perception of public servants of the University of Brasilia regarding the practice of explicit constitutional principles of public administration in the caput of article 37 of the Federal Constitution. Some indicators were proposed to assess self-perception and perception about the practice of principles in the workplace and 893 research questionnaires were applied to the University's staff. The results suggest that the self-perception of to fulfillment is always greater than the perception of such principles in the respondent's work environment. Characteristics such as age and time work in the institution do not seem to interfere with the perception of the practice of the principles. On the other hand, characteristics such as gender, position and the fact of performing a management function are related to a greater or lesser perception of practice of the principles. The results of this work can contribute to institutional self-criticism and to the adoption of measures that improve the observance of such principles.

\footnotetext{
1 Mestrando do Programa de Pós-Graduação em Gestão Pública - Universidade de Brasília - UnB. http://orcid.org/0000-0001-6327-4947 e-mail alissonassisbsb@gmail.com
}

\footnotetext{
2 Possui graduação, mestrado e doutorado em economia pela Universidade Federal de Pernambuco e estágio doutoral na Université Pierre-Mendès-France. Professor do Programa de Pós-Graduação em Gestão Pública - PPGP e do Programa de Pós-Graduação em Gestão e Regulação de Recursos Hídricos ProfÁgua e pesquisador colaborador do Centro de Pesquisas de Opinião Pública da Universidade de Brasília - DATAUnB. E-mail : lula honorato@hotmail.com
} 
KEYWORDS: Principles of public administration; Public administration; UnB; Public servants; LIMPE. JEL: K10, K42, H10

\section{INTRODUÇÃO}

Algumas condutas e práticas são essenciais para o convívio saudável social. Tais coisas ganham maior importância quando se trata do relacionamento que se estabelece entre o Estado, diretamente ou por meio de seus agentes, e o cidadão.

A Constituição Federal de 1988 dedicou um capítulo à Administração Pública, onde são encontrados diversos preceitos sobre a atuação de servidores públicos, acesso a cargos públicos e responsabilidade civil do Estado. Dentre essas normas, estão presentes, no artigo 37 caput, cinco princípios administrativos: legalidade, impessoalidade, moralidade, publicidade e eficiência - LIMPE (BRASIL, 1988). Esses princípios devem pautar a atuação de todos os agentes do Estado, sejam eles pertencentes a qualquer um dos poderes.

Meirelles (2016, p. 92) defende que esses princípios deverão nortear todos os atos e atividades administrativas dos agentes públicos. $O$ autor os define como "fundamentos da ação administrativa", ou por outras palavras, "os sustentáculos da atividade pública" e afirma que a rejeição, pelo agente público, desses princípios, equivale a desconsiderar o que há de mais elementar para a boa guarda e zelo dos interesses sociais. Assim, torna-se fundamental fazer o seguinte questionamento: os servidores públicos agem de acordo com os princípios previstos no artigo 37 ?

O objetivo deste artigo foi o de buscar evidências sobre a percepção dos servidores públicos da Universidade de Brasília a respeito da prática dos princípios constitucionais da Administração Pública explícitos no artigo 37, caput, da Constituição Federal. Os objetivos secundários são: identificar através de indicadores a autopercepção do servidor e a percepção com relação ao ambiente de trabalho sobre o cumprimento dos princípios constitucionais da Administração Pública; e analisar os indicadores encontrados a partir das características pessoais e profissionais dos servidores.

Os resultados obtidos poderão direcionar a Universidade e toda a Administração Pública a adotar medidas preventivas para que todos os agentes públicos tomem conhecimento da importância da prática dos princípios nas atividades desempenhadas, evitando, assim, que atos administrativos sejam invalidados por não estarem de acordo com a norma e possíveis punições aos responsáveis.

\section{OS PRINCÍPIOS JURÍDICOS}

\section{Contexto histórico}

Os princípios passaram por três fases relevantes: a primeira, chamada de jusnaturalismo, a partir do século $\mathrm{XVI}$, tinha como crença o direito natural, onde existiam valores e pretensões humanas não provenientes de uma norma originada pelo Estado. A segunda fase, chamada de positivismo, buscava no final do século XIX a objetividade científica para o Direito, com características similares às ciências exatas e naturais. Até a primeira metade do século XX, os princípios eram tratados apenas 
como orientações, sem caráter coercitivo (BARROSO; BARCELLOS, 2003; MARTINS, 2012).

Com a superação histórica do jusnaturalismo e o fracasso político do positivismo jurídico a partir dos movimentos fascista e nazista, a terceira fase, chamada de "pós-positivismo" surge como uma nova teoria. Segundo Barroso e Barcelos (2003):

O pós-positivismo é a designação provisória e genérica de um ideário difuso, no qual se incluem a definição das relações entre valores, princípios e regras, aspectos da chamada nova hermenêutica constitucional, e a teoria dos direitos fundamentais, edificada sobre o fundamento da dignidade humana. A valorização dos princípios, sua incorporação, explícita ou implícita, pelos textos constitucionais e o reconhecimento pela ordem jurídica de sua normatividade fazem parte desse ambiente de reaproximação entre Direito e Ética (BARROSO e BARCELOS, 2003, p. 147).

No Brasil, os princípios jurídicos presentes nas Constituições anteriores à Carta Magna de 1988 não manifestavam efetividade, tendo em vista "o não reconhecimento de força normativa aos seus textos e da falta de vontade política de dar-lhes aplicabilidade direta e imediata" (BARROSO; BARCELLOS, 2003, p. 142).

\section{A força normativa}

A Constituição busca, por meio de sua força normativa, estabelecer ordem à realidade. Essa força está relacionada com a efetividade plena das normas impostas pela Carta Magna. Para Hesse (1991), a Constituição se torna ativa se as tarefas por ela impostas forem efetivamente realizadas, existindo a vontade da sociedade em agir de acordo com a ordem estabelecida por ela. Assim, a Constituição deve estar de acordo com a realidade jurídica do Estado e compatível com a realidade social.

Canotilho (2003) considera que a garantia da força normativa constitucional não é uma tarefa fácil. Porém, se o direito constitucional é direito positivo, ou seja, possui normas elaboradas por uma determinada sociedade para conduzir a vida social durante determinada época, e se a constituição vale como lei, então tanto regras quanto os princípios constitucionais devem possuir normatividade.

Hesse (1991, p.22) afirma que:

Quem se mostra disposto a sacrificar um interesse em favor da preservação de um princípio constitucional fortalece o respeito à Constituição e garante um bem da vida indispensável à essência do Estado, mormente ao Estado democrático.

Bandeira de Mello (2013) declara que a violação de um princípio é um ato grave. Quando não se obedece a um princípio, todo o sistema de comandos é descumprido e não apenas um específico mandamento obrigatório. Para o autor essa é uma importante forma de ilegalidade ou inconstitucionalidade, já que vai contra todo o sistema e denota insubordinação de valores fundamentais.

\section{Os dois tipos de normas: princípios e regras}

As normas são "preceitos que tutelam situações subjetivas de vantagem ou de vínculo" (SILVA, 2005, p.91). Por um lado, elas permitem a realização de interesses de pessoas ou entidades por ato próprio ou exigindo a ação ou abstenção de outrem. 
Por outro lado, elas submetem indivíduos ou entidades ao dever de cumprir as exigências de realização de uma prestação, ação ou abstenção a favor de outrem. (SILVA, 2005).

Barroso (2009) defende que a distinção entre norma e princípio não é mais discutida pelos autores do direito, pois já se encontra superada. Segundo o autor, o debate atual está concentrado em duas categorias de normas: as normas-princípio, também referidas como princípios, e as normas-disposição, ou simplesmente regras.

Existe uma discussão no meio jurídico sobre a distinção entre regras e princípios como espécies normativas. Sousa (2011) afirma que há, na doutrina, pelo menos duas ou três posições sobre a diferenciação entre princípio e regra. Uma corrente, composta principalmente por Ronald Dworkin e Robert Alexy, defende uma distinção "forte", onde há uma diferença de caráter lógico entre princípios e regras. Outros autores, como Humberto Ávila e Aulis Aarnio, acreditam em uma distinção "fraca", onde a diferença entre regras e princípios é apenas de grau, seja de grau de fundamentalidade, abstração ou generalidade. Por outro lado, Günther (2004) assegura que não existe uma diferença estrutural entre princípios e regras. Neste artigo, a definição de regra e de princípio assumida é aquela considerada como distinção "forte", apresentada por Robert Alexy:

Princípios são normas que ordenam que algo seja realizado na maior medida possível dentro das possibilidades jurídicas e fáticas existentes. Princípios são, por conseguinte, mandamentos de otimização, que são caracterizados por poderem ser satisfeitos em graus variados e pelo fato de que a medida devida de sua satisfação não depende somente das possibilidades fáticas, mas também das possibilidades jurídicas. [...] Já as regras são normas que são sempre ou satisfeitas ou não satisfeitas. Se uma regra vale, então, deve se fazer exatamente aquilo que ela exige; nem mais, nem menos (ALEXY, 2008, p. 90).

Barroso (2009) afirma que a interpretação constitucional deve sempre ser iniciada pela identificação do princípio maior que rege o assunto a ser observado, começando pelo mais genérico até chegar à norma mais específica, ou seja, na regra concreta. Porém, o autor declara que não existe hierarquia entre princípio e regra, isto é, encontram-se no mesmo plano. Canotilho (2003, p. 1184) destaca que:

[...] embora a Constituição possa ser uma "unidade dividida" [...] dada a diferente configuração e significado material de suas normas, isso em nada altera a igualdade hierárquica de todas as suas regras e princípios quanto à sua validade, prevalência normativa e rigidez.

\section{Os princípios administrativos}

Os princípios fundamentais que orientam todas as atividades desempenhadas pela Administração Pública estão explícitos ou implícitos na Constituição de 1988 e em leis esparsas. São doze itens de observação obrigatória e permanente para toda a Administração Pública: Legalidade, Impessoalidade, Moralidade, Publicidade, Eficiência (LIMPE), Razoabilidade, Proporcionalidade, Ampla Defesa, Contraditório, Segurança Jurídica, Motivação e Supremacia do Interesse Público. Os cinco primeiros são citados explicitamente no artigo 37, caput, da Lei Maior. Os demais se encontram implícitos na Constituição ou na legislação - principalmente na Lei n. 9.784/1999, que trata dos processos administrativos (MEIRELLES, 2016; BRASIL, 1999). 
Carvalho Filho (2018) assevera que os princípios administrativos são premissas fundamentais que influenciam o modo de agir da Administração Pública, em outras palavras, são norteadores da conduta do Estado quando este executa ações administrativas. O artigo $4^{\circ}$ da Lei $n . \stackrel{0}{ } 8.429$ de 1992 (Lei de Improbidade Administrativa) prevê que todos os agentes públicos devem obedecer aos princípios de legalidade, impessoalidade, moralidade e publicidade (o princípio da eficiência não é citado no artigo, pois a lei de improbidade é anterior à Emenda Constitucional n. -19 de 1998, a qual deu origem ao novo princípio). Dessa forma, o disposto no artigo demanda pleno cumprimento, ou seja, impõe aos agentes públicos o dever da estrita observância dos princípios constitucionais da Administração Pública (FAZZIO JúNIOR, 2016).

\section{Os princípios constitucionais da Administração Pública contidos no artigo 37 da Constituição Federal}

\section{Legalidade}

O princípio da legalidade é um dos fundamentos do Estado de Direito e configura como uma garantia fundamental de todo indivíduo. Esse princípio surgiu nas Revoluções que aconteceram no fim do século XVIII e seu objetivo era de estabelecer limites aos governantes da época e assegurar liberdades individuais para o povo (AITH, 2004).

O princípio da legalidade previsto no artigo 37 da Constituição vigente:

Significa que o administrador público está, em toda a sua atividade funcional, sujeito aos mandamentos da lei e às exigências do bem comum, e deles não se pode afastar ou desviar, sob pena de praticar ato inválido e expor-se a responsabilidade disciplinar, civil e criminal, conforme o caso (MEIRELLES, 2016, p.93).

A Administração Pública é subordinada ao princípio da legalidade. Ela deve tão somente aceitá-lo e colocá-lo em prática. Todas as atividades dos agentes públicos, desde o Presidente da República até o mais modesto dos servidores, deverão estar de acordo com as disposições gerais fixadas pelo Poder Legislativo (BANDEIRA DE MELLO, 2013). Meirelles (2016) afirma que na Administração Pública não existe liberdade e muito menos vontade pessoal. Na administração particular é permitido fazer tudo aquilo que a lei não proíbe. Entretanto, na Administração Pública só é permitido fazer o que a lei autoriza. Nas palavras do autor, "a lei para o particular significa 'pode fazer assim'; para o administrador público significa 'deve fazer assim'” (MEIRELLES, 2016, p.93).

Resoluções, portarias, deliberações e instruções normativas são consideradas fontes administrativas de observância obrigatória na esfera do ente público ou da atividade pública que rege, pois elas moldam a legalidade. Esses documentos devem cumprir obrigatoriamente as regras preestabelecidas em normas superiores. Obviamente, eles devem respeitar as normas preestabelecidas em fontes superiores, expedidas pelo Legislativo (MARRARA, 2013).

\section{Impessoalidade}

No período das monarquias absolutistas, a conhecida pessoalidade estatal predominava entre as autoridades. Todas as ações surgiam a partir das conveniências 
do Rei, gerando ao povo a falta de previsibilidade e segurança jurídica. O nascimento do Estado Democrático de Direito trouxe a necessidade da despersonalização do poder, de forma a representar um ideal de justiça comum, sem privilégios, isenta, objetivando a coisa pública ao invés da privada (LIMA; OLIVEIRA; NETO, 2010).

A exigência de impessoalidade pode ser entendida de duas formas: a primeira possui relação com a finalidade pública, a qual deve conduzir toda a atividade administrativa. Significa que a impessoalidade deve ser observada em relação aos administrados, de forma que a Administração não atue com o intuito de prejudicar ou beneficiar pessoas determinadas, pois é o interesse público que deve nortear o comportamento de toda a Administração Pública. A segunda forma quer dizer que a impessoalidade deve ser analisada do ponto de vista da Administração, ou seja, os atos e provimentos administrativos são atribuídos ao órgão ou entidade administrativa, e não ao agente público que Ihes deu origem (DI PIETRO, 2018; SILVA, 2005).

Bandeira de Mello (2013, p. 117) explica o princípio da impessoalidade da seguinte forma:

Nele se traduz a ideia de que a Administração tem que tratar todos os administrados sem discriminações, benéficas ou detrimentosas. Nem favoritismo nem perseguições são toleráveis. Simpatias ou animosidades pessoais, políticas ou ideológicas não podem interferir na atuação administrativa e muito menos interesses sectários, de facções ou grupos de qualquer espécie (MELLO, 2013, p. 117).

A prática de ato administrativo que não possua interesse público ou conveniência para a Administração, por favoritismo ou perseguição dos agentes governamentais, com o objetivo de satisfazer interesses pessoais, denota um desvio de conduta do agente público, consistindo em uma das modalidades de abuso de poder (MEIRELLES, 2016).

\section{Moralidade}

Para Hauriou (1926, p. 197, apud MEIRELLES, 2016, p. 94), a moralidade administrativa não é a moralidade comum, mas moralidade jurídica. Ele a define como o "conjunto de regras de conduta tiradas da disciplina interior da Administração". O autor explica que o agente administrativo, com sua capacidade humana de atuação, deve distinguir o bem do mal, o honesto do desonesto, o justo do injusto, 0 conveniente do inconveniente, o oportuno do inoportuno. $O$ ato administrativo terá que obedecer, além da lei jurídica, a lei ética da própria Instituição, pois nem tudo aquilo que é legal é honesto.

Sobre a distinção entre a moralidade comum e a moralidade administrativa, Moreira Neto (2014, p. 102) afirma que, "enquanto a moral comum é orientada por uma distinção puramente ética, entre o bem e o mal, distintamente, a moral administrativa é orientada por uma diferença prática entre a boa e a má administração". Entretanto, Di Pietro (2018, p. 119) considera que "mesmo os comportamentos ofensivos da moral comum implicam ofensa ao princípio da moralidade administrativa".

Bandeira de Mello (2013, p. 122) considera que, de acordo com o princípio da moralidade, "a Administração e seus agentes têm de atuar na conformidade de princípios éticos". O autor acresce que os princípios da lealdade e da boa-fé compreendem o âmbito do princípio da moralidade. Portanto, a Administração deverá agir com sinceridade perante os administrados, sendo proibido qualquer 
comportamento com o intuito de confundir, dificultar ou minimizar o exercício dos direitos dos cidadãos.

Di Pietro (2018) assevera que o princípio da moralidade também deve ser observado pelo particular que se relaciona com a Administração Pública e traz como exemplo os frequentes conluios entre licitantes como forma de ofensa ao referido princípio. A autora afirma ainda que:

[...] sempre que em matéria administrativa se verificar que o comportamento da Administração ou do administrado que com ela se relaciona juridicamente, embora em consonância com a lei, ofende a moral, os bons costumes, as regras de boa administração, os princípios de justiça e de equidade, a ideia comum de honestidade, estará havendo ofensa ao princípio da moralidade administrativa (DI PIETRO, 2018, p. 119).

\title{
Publicidade
}

No Brasil, a publicidade das ações do governo foi uma reivindicação geral de democracia administrativa. A partir da década de 50 e, mais fortemente na de 70, a falta de divulgação de informações sobre a atividade administrativa mostrava-se contrária às características de um Estado Democrático de Direito e destoava dos países mais desenvolvidos. A Constituição de 1988 alinhou a tendência de publicidade das práticas da Administração Pública, invertendo o aspecto oculto que predominava no período do governo militar (MEDAUAR, 2018).

Para Meirelles (2016, p. 100) a "publicidade é a divulgação oficial do ato para conhecimento público e início de seus efeitos externos". A exigência de publicidade de leis, atos e contratos administrativos é justificada pelo autor pelo fato de adquirirem validade perante as partes interessadas e terceiros somente após a publicação em um meio acessível. O princípio da publicidade engloba toda a Administração Pública e não é exercido apenas através de divulgações oficiais, mas também mediante a propiciação de conhecimento da atuação interna dos seus agentes. Essa publicidade abrange:

\begin{abstract}
Os atos concluídos e em formação, os processos em andamento, os pareceres dos órgãos técnicos e jurídicos, os despachos intermediários e finais, as atas de julgamentos das licitações e os contratos com quaisquer interessados, bem como os comprovantes de despesas e as prestações de contas aos órgãos competentes. Tudo isto é papel ou documento público que pode ser examinado na repartição por qualquer interessado, e dele pode obter certidão ou fotocópia autenticada para os fins constitucionais (MEIRELLES, 2016, p. 101).
\end{abstract}

Os atos da Administração devem ter divulgação abundante entre os administrados através de meios que permitam fácil acesso - publicação em órgãos de imprensa, fixação em locais de grande circulação, disponibilização através de mecanismos tecnológicos, como é o caso da internet. Através da transparência é que os indivíduos conseguirão avaliar a legalidade ou não das práticas administrativas. (CARVALHO FILHO, 2018; BANDEIRA DE MELLO, 2013).

Em 2011 foi promulgada a Lei no 12.527, conhecida como Lei de Acesso à Informação. Ela passou a regular o direito à informação e o direito de acesso a registros e informações nos órgãos públicos (BRASIL, 2011). A norma prevê que qualquer negativa de informação por parte da Administração Pública deve ter motivação específica, sob pena de responsabilização do agente que a negou (CARVALHO FILHO, 2018). 


\section{Eficiência}

O princípio da eficiência remete ao modo gerencial privado, onde a ideia de eficiência está na racionalização dos custos para geração de lucro financeiro, com mais agilidade, flexibilidade e otimização de resultados. A eficiência estava presente no texto original da Constituição de 1988 no artigo 74, inciso II, o qual prevê um sistema de controle interno, integrado aos três poderes, com o objetivo de comprovar a legalidade e avaliar resultados, quanto à eficiência e eficácia, da gestão orçamentária, financeira e patrimonial nos órgãos e entidades da administração federal. A eficiência também aparece no artigo 175, parágrafo único, inciso IV, que prevê a elaboração de lei sobre a obrigação de oferecimento de serviço público adequado. Todavia, foi a Emenda Constitucional n. .19 de 1988 que incluiu a eficiência como um princípio expresso no caput do artigo 37 da Constituição Federal (BRASIL, 1988; MUNIZ, 2007).

Para Meirelles (2016, p. 105), "o princípio da eficiência exige que a atividade administrativa seja exercida com presteza, perfeição e rendimento funcional". A função administrativa exige mais do que apenas a legalidade, ela requer resultados positivos para o serviço público e atendimento dos anseios da população. O princípio, segundo o autor, "deve ser entendido e aplicado no sentido de que a atividade administrativa (causa) deve buscar e produzir um resultado (efeito) razoável em face do atendimento do interesse público visado".

Di Pietro (2018, p. 122) entende que o princípio da eficiência aponta dois aspectos: o primeiro é o "modo de atuação do agente público", de onde se deseja um desempenho otimizado a fim de obter melhores resultados; o segundo é o "modo de organizar, estruturar e disciplinar a Administração Pública", também com a finalidade de melhorar a prestação do serviço público.

\section{MÉTODO}

Este capítulo se destina a apresentar a metodologia aplicada no desenvolvimento da pesquisa, sobretudo acerca da forma de coleta de dados e dos métodos estatísticos que foram utilizados.

\section{Produção dos dados}

A Universidade de Brasília (UnB) é uma Instituição pública de ensino superior, integrante da Fundação Universidade de Brasília, criada pela Lei $\mathrm{n} .{ }^{\circ}$ 3.998/1961. Ela faz parte da Administração Pública Indireta, sendo considerada uma autarquia. Assim como ocorre na administração direta, o seu corpo de trabalhadores é formado por servidores públicos, dividido entre os cargos de docente e de técnicoadministrativo em educação. Para ingresso, ambos os cargos exigem a aprovação em concurso público (BRASIL, 1961; UNB, 2011; BRASIL, 1990).

Tantos os servidores técnicos quanto os docentes estão submetidos aos mandamentos contidos no caput do artigo 37 da Carta Magna, pois estes se 
relacionam com o Estado e estão subordinados seu regime prevalente de direito público, devendo respeitar a atender a todos os princípios da Administração Pública (BONAVIDES; MIRANDA; AGRA, 2009).

Os dados foram produzidos através de um questionário dividido em três partes: a primeira parte possui questões fechadas, onde foram coletados dados acerca de atitudes percebidas pelo entrevistado diante da atuação dos colegas de trabalho nas atividades realizadas no âmbito da Administração Pública. A segunda seção também é composta por questões fechadas e teve por finalidade coletar dados sobre as atitudes do próprio entrevistado no ambiente de trabalho. A parte final coletou informações sociais e profissionais do entrevistado como idade, gênero, tempo trabalhado na Universidade de Brasília, cargo (técnico-administrativo ou docente) e função de gestão. Para esta pesquisa, considera-se função de gestão qualquer cargo de chefia exercido na Universidade, como diretor, coordenador, secretário, decano, etc. Por fim, o entrevistado respondeu se conhecia a legislação pertinente acerca do dever de probidade administrativa. O questionário se encontra no apêndice deste artigo.

As questões contidas nas duas primeiras seções do questionário possuem a forma de afirmação e todas têm relação direta com os princípios constitucionais da Administração Pública. Essas seções contêm dez afirmações cada, sendo duas questões para cada um dos princípios (legalidade, impessoalidade, moralidade, eficiência e publicidade - LIMPE). A primeira parte do questionário buscou obter dados da percepção do entrevistado sobre a prática dos princípios pelos colegas de trabalho. A partir de agora essa percepção será chamada "ambiente de trabalho". A segunda parte objetivou coletar dados do entrevistado sobre si mesmo acerca da prática dos princípios. Essa percepção será denominada "autopercepção".

As afirmações contidas nos questionários foram baseadas nos textos escritos pelos doutrinadores ou em legislações citadas no referencial teórico desta pesquisa. As respostas utilizam um padrão baseado no modelo desenvolvido por Likert (1932), onde os respondentes precisam marcar uma opção em um sistema de cinco categorias. Foram feitas afirmações sobre atitudes observadas pelo entrevistado e este escolheu apenas uma das seguintes opções de respostas: a) nunca acontece; b) quase nunca acontece; c) às vezes acontece, outras vezes não; d) quase sempre acontece; e) sempre acontece.

Os questionários foram enviados para servidores ativos (docentes e técnicoadministrativos em educação) da Universidade de Brasília (UnB) entre junho e julho de 2019. Em junho de 2019, a UnB possuía 6.063 servidores (UNB, 2019). Os entrevistados receberam o questionário através de e-mail onde foi incluído um link para uma página da internet que possibilitou o preenchimento e armazenamento das respostas.

Os endereços de e-mail dos servidores foram solicitados formalmente à Universidade, porém o pedido foi negado sob a alegação de que os dados caracterizam informações pessoais dos servidores, pois a maioria dispõe apenas de e-mail pessoal cadastrado no sistema de registro de pessoal. Assim, buscas foram realizadas em documentos públicos e páginas da internet da Universidade com a finalidade de coletar o máximo de endereços de e-mail possíveis. Dessa forma, foram coletados 4.539 e-mails.

O questionário passou por um processo de validação ao ser analisado criticamente por especialistas e testado em simulações. 


\section{Análise dos dados}

Para cada resposta do entrevistado sobre as questões relativas aos princípios constitucionais da Administração Pública foi atribuído um valor, conforme o Quadro 1. O padrão de respostas foi construído com base no modelo desenvolvido por Likert (1932).

Quadro 1. Valor atribuído às respostas do entrevistado

\begin{tabular}{|l|c|}
\hline \multicolumn{1}{|c|}{ Resposta } & Valor \\
\hline Nunca acontece & -2 \\
\hline Quase nunca acontece & -1 \\
\hline Ás vezes acontece, outras vezes não & 0 \\
\hline Quase sempre acontece & 1 \\
\hline Sempre acontece & 2 \\
\hline
\end{tabular}

Fonte: elaborado pelo autor

Quanto mais próximo de "2", maior a percepção do entrevistado sobre a prática daquele princípio. Por outro lado, quanto mais perto de "-2", menor essa percepção. Para chegar ao resultado sobre a prática de um dos princípios, foi realizada uma média dos valores obtidos nas duas questões respondidas pelo entrevistado sobre o princípio avaliado, denominado índice LIMPE, conforme o Quadro 2.

Quadro 2. Cálculo dos índices LIMPE

\begin{tabular}{|l|c|c|}
\hline Princípios & Ambiente de trabalho & Autopercepção \\
\hline Legalidade & $L_{C}=\frac{l_{1}+l_{2}}{2}$ & $L_{A}=\frac{l_{11}+l_{12}}{2}$ \\
\hline Impessoalidade & $I_{C}=\frac{i_{3}+i_{4}}{2}$ & $I_{A}=\frac{i_{13}+i_{14}}{2}$ \\
\hline Moralidade & $M_{C}=\frac{m_{5}+m_{6}}{2}$ & $M_{A}=\frac{m_{15}+m_{16}}{2}$ \\
\hline Publicidade & $P_{C}=\frac{p_{7}+p_{8}}{2}$ & $P_{A}=\frac{p_{17}+p_{18}}{2}$ \\
\hline Eficiência & $E_{C}=\frac{e_{9}+e_{10}}{2}$ & $E_{A}=\frac{e_{19}+e_{20}}{2}$ \\
\hline
\end{tabular}

Fonte: elaborado pelo autor

Onde:

- $L, I, M, P, E$ : referem-se aos os índices relativos à prática dos princípios da Legalidade, Impessoalidade, Moralidade, Publicidade e Eficiência, respectivamente.

- $\quad l, i, m, p$, e: indicam que aquela questão se referiu ao princípio da legalidade ou impessoalidade ou moralidade ou publicidade ou eficiência, respectivamente. $\mathrm{O}$ número que acompanha a letra refere-se ao número da questão;

- "A" indica que aquela questão ou índice está relacionado à avaliação individual sobre determinado princípio (autopercepção);

- " $c$ " indica que aquela questão ou índice está relacionado à avaliação do servidor sobre a prática de determinado princípio no ambiente de trabalho. 
Após o cálculo da percepção sobre cada princípio, foi determinada a percepção sobre a prática dos princípios constitucionais da Administração Pública através do cálculo da média dos resultados obtidos, conforme o Quadro 3.

Quadro 3. Cálculo da percepção sobre os princípios

\begin{tabular}{|l|c|}
\hline $\begin{array}{l}\text { Cálculo da percepção relativa à prática dos princípios } \\
\text { constitucionais da Administração Pública no ambiente de } \\
\text { trabalho (indicador "C") }\end{array}$ & $C=\frac{L_{c}+I_{c}+M_{c}+P_{c}+E_{c}}{5}$ \\
\hline $\begin{array}{l}\text { Cálculo da autopercepção sobre a prática dos princípios } \\
\text { constitucionais da Administração Pública (indicador "A") }\end{array}$ & $A=\frac{L_{A}+I_{A}+M_{A}+P_{A}+E_{A}}{5}$ \\
\hline
\end{tabular}

Fonte: elaborado pelo autor

Onde: $-2>=C, A=>2$.

Observe que quanto mais próximo de menos dois o indicador representa uma menor percepção sobre a prática ou o cumprimento dos princípios. De maneira oposta, quanto mais próximo de dois, maior a percepção.

\section{Análise descritiva}

Os dados foram apresentados através de análise descritiva, com a utilização de medidas de síntese, gráficos e tabelas que mostrem as informações de maneira resumida e organizada, com a finalidade de exibir os resultados obtidos através dos índices e indicadores propostos e dos dados coletados na terceira parte do questionário.

\section{DISCUSSÃO DOS RESULTADOS}

\section{Análise dos indicadores}

A aplicação do questionário obteve 902 respostas, sendo que nove foram descartadas por erros de preenchimento de dados relativos a informações sociais e profissionais. Assim, a análise foi efetuada com base em 893 respondidos.

A fim de se entender melhor as características gerais dos dados utilizados nesta pesquisa, a Tabela 1 exibe algumas estatísticas descritivas obtidas na seção 3 do questionário submetido aos entrevistados. A tabela apresenta a média, a estatística moda, o desvio padrão e os valores de máximo e mínimo de cada variável.

Tabela 1. Estatísticas descritivas envolvidas na pesquisa

\begin{tabular}{lccccc}
\hline Características & Média & Moda & DP & Máx. & Mín. \\
\hline Idade & 41,840 & 39 & 10,960 & 85 & 23 \\
Tempo trabalhado Universidade (em anos) & 10,812 & 3 & 9,818 & 64 & 0 \\
Gênero & 0,527 & Feminino & 0,499 & - & - \\
Cargo & 0,634 & Téc. Adm. & 0,482 & - & - \\
Exerce função de gestão & 0,815 & Não & 0,388 & - & - \\
Conhece a legislação sobre improbidade & 0,819 & Sim & 0,385 & - & - \\
\hline
\end{tabular}

Fonte: dados da pesquisa

A idade média dos entrevistados é de quase 42 anos e o tempo médio trabalhado na Universidade é de quase 11 anos. Observa-se que a amostra possui $52,7 \%$ de indivíduos do sexo feminino, $63,4 \%$ possuem o cargo de Técnico- 
Administrativo em Educação e $81,5 \%$ dos entrevistados não exercem função de gestão. Sobre a legislação pertinente acerca do dever de probidade administrativa, $81,9 \%$ dos entrevistados afirmaram conhecê-la.

Tendo por base o cálculo dos índices LIMPE e dos indicadores A e C, conforme - Quadro 2, a Tabela 2 é apresentada a seguir com os resultados sobre a prática de cada princípio Constitucional da Administração Pública. Esses resultados foram alcançados através da média dos valores obtidos pelos índices LIMPE de todos os entrevistados.

Tabela 2. Resultado da percepção de todos os entrevistados sobre a prática dos princípios

\begin{tabular}{lcc}
\hline Princípios & $\begin{array}{c}\text { Ambiente de trabalho } \\
\text { Indicador C }\end{array}$ & $\begin{array}{c}\text { Autopercepção } \\
\text { Indicador A }\end{array}$ \\
\hline Legalidade & $L_{C}=0,607$ & $L_{A}=1,297$ \\
Impessoalidade & $I_{C}=0,237$ & $I_{A}=1,442$ \\
Moralidade & $M_{C}=0,860$ & $M_{A}=1,783$ \\
Publicidade & $P_{C}=1,372$ & $P_{A}=1,655$ \\
Eficiência & $E_{C}=0,605$ & $E_{A}=1,549$ \\
\hline Total & $C=0,736$ & $A=1,545$ \\
\hline
\end{tabular}

Fonte: dados da pesquisa

Os dados da tabela mostram que o indicador $\mathrm{C}$ é de, em média, 0,736. Dessa forma, a prática dos princípios LIMPE no ambiente de trabalho é percebida de maneira positiva, considerando que o indicador varia entre -2 a 2 . Já o indicador de autopercepção (A) é de, em média, 1,545. Tal resultado mostra que a autopercepção sobre a prática dos princípios é muito superior à percepção da prática no ambiente de trabalho. Este resultado já era esperado tendo em vista que a autocrítica parece ser sempre menor que a crítica a outros ou a instituições. Sugere-se que uma possível sobreavaliação dos servidores sobre si próprios tenha ocorrido.

$O$ índice $I_{c}$ obteve a média de 0,237. Assim sendo, considera-se que os servidores percebem a aplicação da impessoalidade. Apesar de o índice não apresentar número negativo, há evidências de que a impessoalidade é o princípio que os servidores menos verificam no ambiente de trabalho, pois, em comparação com os demais, ele obteve o menor valor dentre os índices propostos.

Por outro lado, a autopercepção sobre a prática da impessoalidade obteve média de 1,422 . Esse valor médio é $500 \%$ maior que a média obtida na avaliação sobre a percepção do mesmo princípio no ambiente de trabalho. Possivelmente o servidor consegue perceber com certa facilidade, na conduta dos colegas de trabalho, decisões tomadas com base em interesses pessoais, políticos e ideológicos. 0 mesmo parece não acontecer em sua autoavaliação.

O índice $P_{C}$ obteve a maior média na avaliação da percepção dos princípios no ambiente de trabalho e o índice $P_{A}$ apresentou a segunda maior média na avaliação de autopercepção. As facilidades promovidas pelas tecnologias e as exigências impostas pela lei de acesso à informação podem ser algumas das prováveis explicações para esse resultado.

O indicador $M_{A}$ revelou o maior índice de percepção da pesquisa. Assim, podese sugerir que os servidores, na maioria das vezes, consideram que suas próprias ações estão de acordo com a moralidade imposta pela constituição.

A percepção sobre a prática dos princípios constitucionais da Administração Pública explícitos no artigo 37 da Constituição apresentam, nas análises efetuadas, médias entre 0 e 2 . A prática não é percebida em $100 \%$ dos casos, mas na maioria 
das vezes os servidores confirmam que tanto seus atos quanto os atos realizados no ambiente de trabalho estão de acordo com os princípios LIMPE. Isso pode ser reflexo dos $81,9 \%$ dos entrevistados que afirmaram ter conhecimento sobre legislação pertinente acerca do dever de probidade administrativa.

Entretanto, ao visualizar os dados brutos, percebem-se alguns casos isolados onde os princípios previstos no artigo 37 podem não estar sendo aplicados. A tabela 3 revela o quantitativo de servidores que não perceberam a aplicação dos princípios LIMPE dentre os 893 entrevistados que responderam ao questionário.

Tabela 3. Quantitativo de servidores que não perceberam a aplicação dos princípios LIMPE

\begin{tabular}{lcc}
\hline Princípios & No ambiente de trabalho & Na própria conduta \\
\hline Legalidade & 72 & 14 \\
Impessoalidade & 159 & 15 \\
Moralidade & 30 & 1 \\
Publicidade & 14 & 8 \\
Eficiência & 67 & 1 \\
\hline
\end{tabular}

Fonte: dados da pesquisa

A referida tabela apresenta o quantitativo de servidores que avaliaram que a prática dos princípios LIMPE quase nunca acontece (-1) ou nunca acontece (-2), utilizando como referência o cálculo dos índices LIMPE (Quadro 2). São nessas situações que a Administração Pública deve intervir, de forma a identificar onde estão ocorrendo as práticas contrárias aos princípios administrativos e tomar as medidas necessárias.

Dos 893 entrevistados, 159, ou seja, quase $18 \%$ dos entrevistados consideram que a prática do princípio da impessoalidade no ambiente de trabalho quase nunca acontece ou nunca acontece. Isso reflete o resultado obtido no índice $I_{c}$, de 0,237. Menos de $10 \%$ informou que os princípios da legalidade e eficiência não estão sendo aplicados no ambiente de trabalho. Essa taxa é menor que $5 \%$ na avaliação da prática dos princípios da moralidade e publicidade no ambiente de trabalho. Sobre a autopercepção, menos de $4 \%$ dos servidores não percebem na própria conduta a prática dos princípios LIMPE.

\section{Análise a partir das características pessoais e profissionais}

A seguir serão feitas análises dos resultados dos indicadores a partir da idade, do tempo de trabalho na Universidade, do gênero, do cargo e, por fim, da função de gestão. A figura 1 apresenta a percepção dos servidores de acordo com a idade. 
Figura 1. Percepção dos entrevistados de acordo com a idade

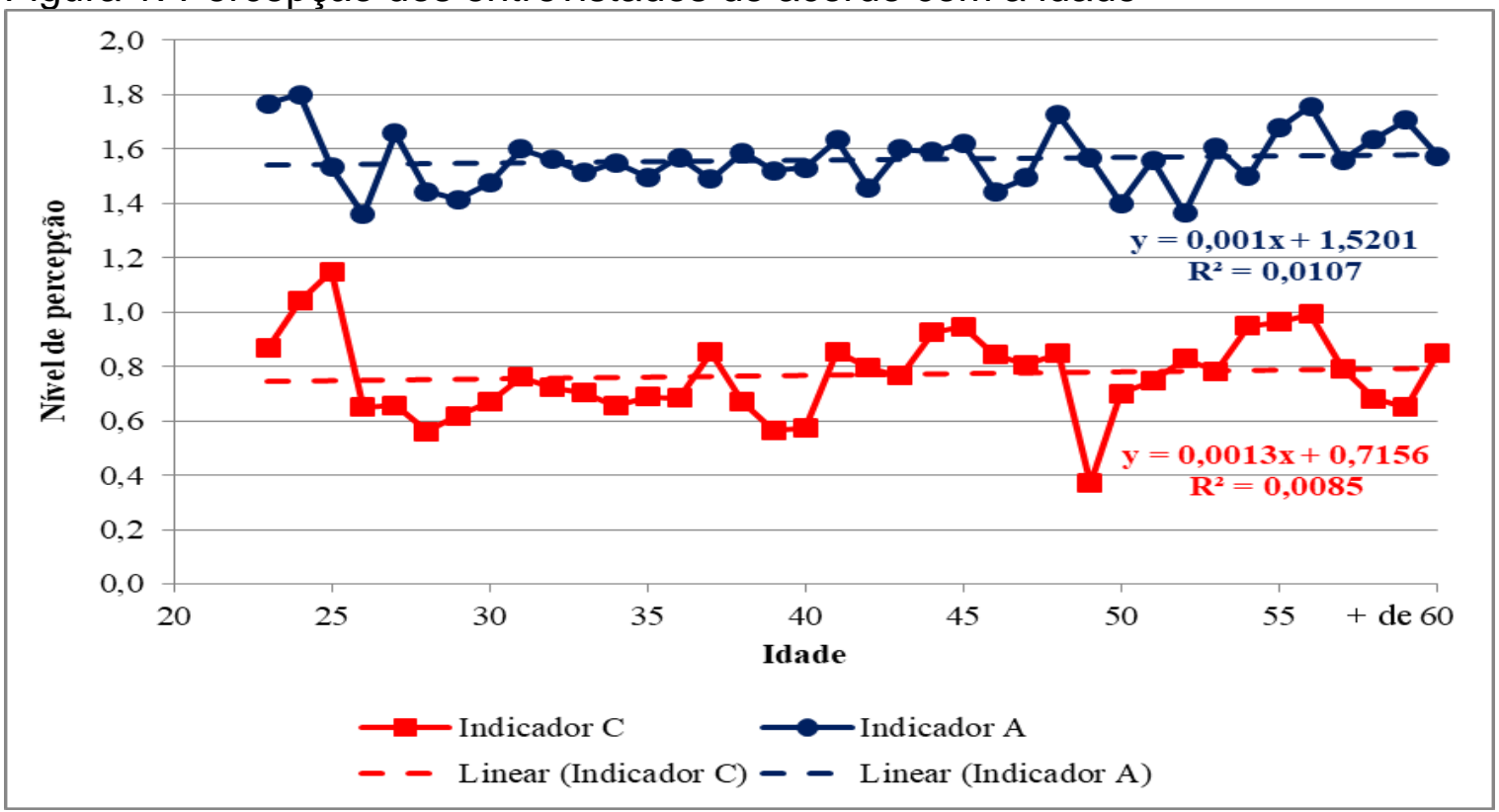

Fonte: dados da pesquisa

De acordo com a figura, a percepção sobre a prática dos princípios LIMPE no ambiente de trabalho têm uma tendência estável conforme o servidor vai ficando mais velho. O mesmo acontece com a autopercepção.

A figura 2 mostra a percepção dos servidores de acordo com o tempo trabalhado.

Figura 2. Percepção dos entrevistados de acordo com o tempo trabalhado na Universidade

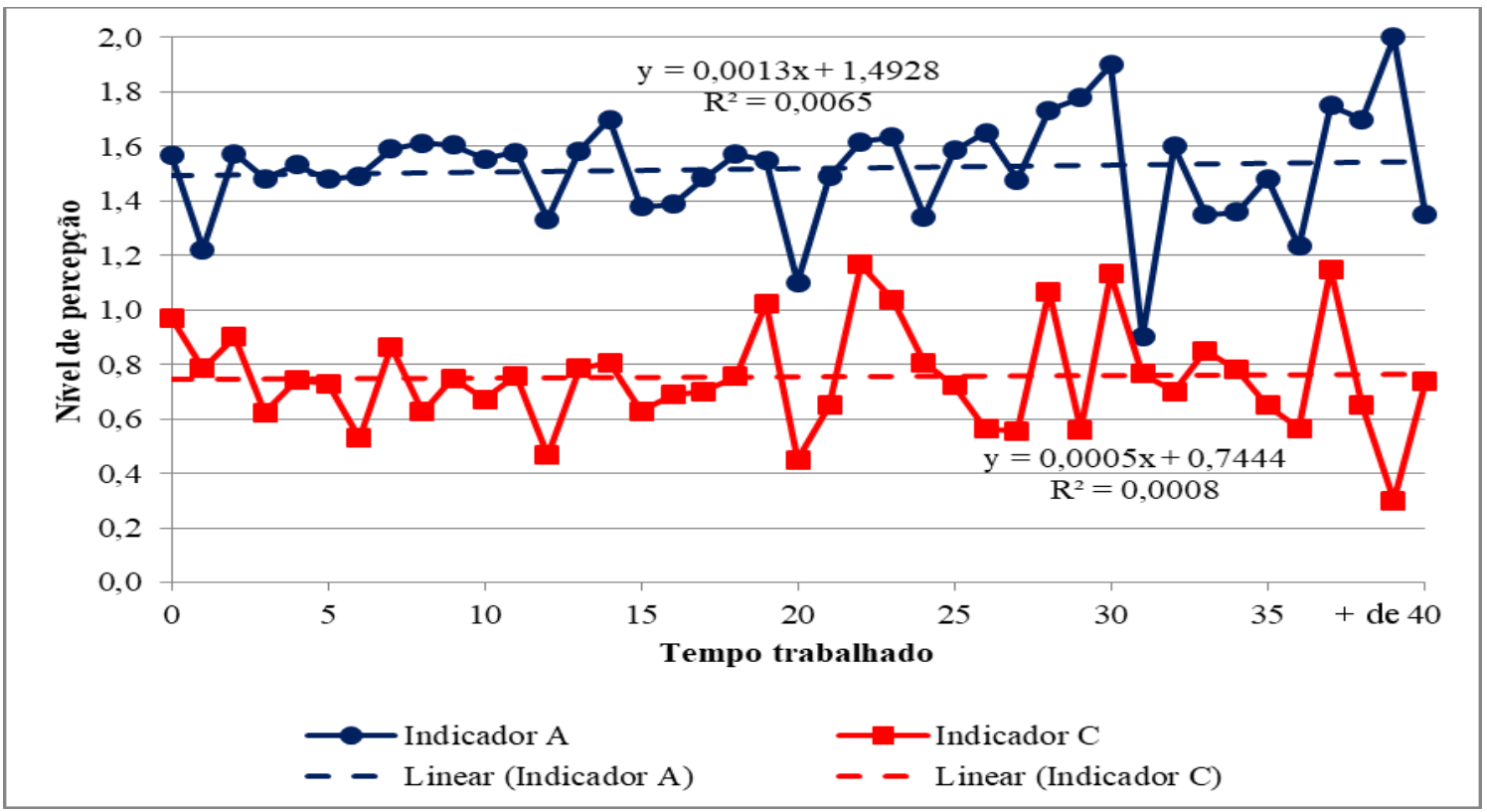

Fonte: dados da pesquisa

Os dados apresentados na referida figura revelam que a linha de tendência do indicador $\mathrm{C}$ permanece praticamente horizontal, indicando que o tempo de trabalho na Universidade possivelmente não interfere na percepção do servidor sobre a prática 
do LIMPE no ambiente de trabalho. O mesmo acontece com a linha de tendência do indicador A, apontando que a autopercepção dos servidores sobre a prática dos princípios tende a permanecer praticamente inalterada conforme o tempo trabalhado na Instituição.

A Figura 3 apresenta a percepção dos entrevistados de acordo com o gênero.

Figura 3. Percepção dos entrevistados de acordo com o gênero

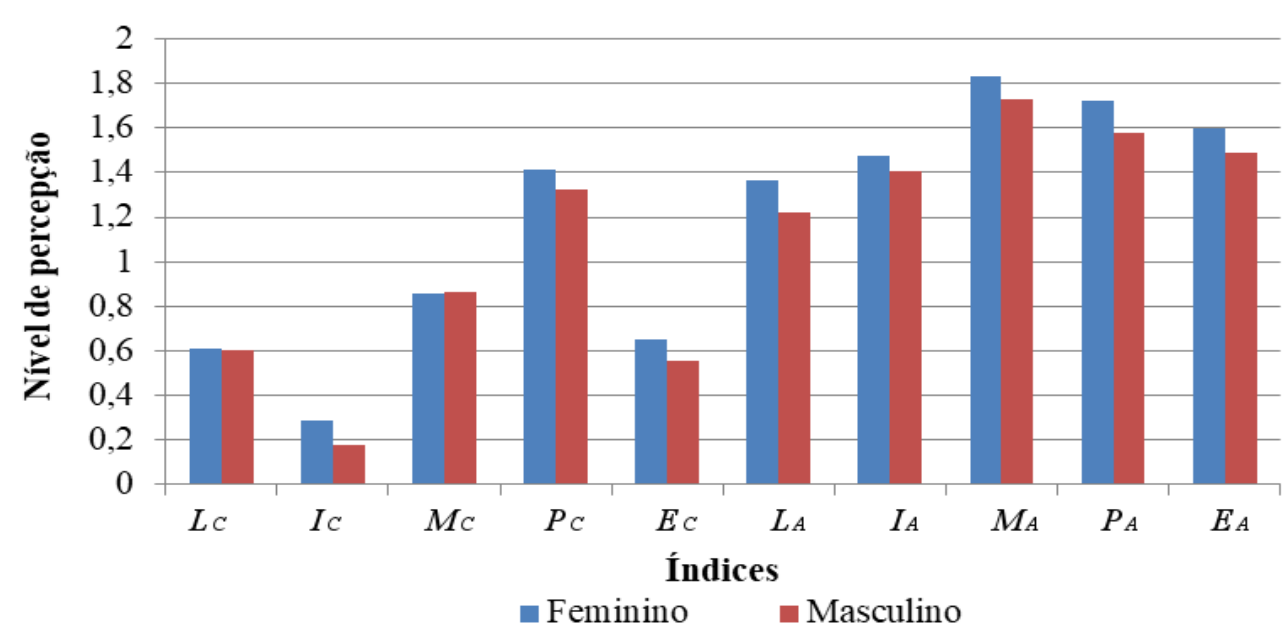

Fonte: dados da pesquisa

A referida figura mostra que as mulheres possuem a percepção sobre a prática dos princípios LIMPE discretamente melhor em comparação aos homens. Os índices delas são, em média, 0,111 mais altos que os deles. Apenas nos índices $L_{c}$ e $M_{c}$ essa diferença não é observada. Sugere-se que os homens avaliam a percepção sobre a prática dos princípios LIMPE com uma visão mais crítica que as mulheres.

A Figura 4 apresenta a percepção dos entrevistados de acordo com o cargo exercido na Universidade.

Figura 4. Percepção dos entrevistados de acordo com o cargo

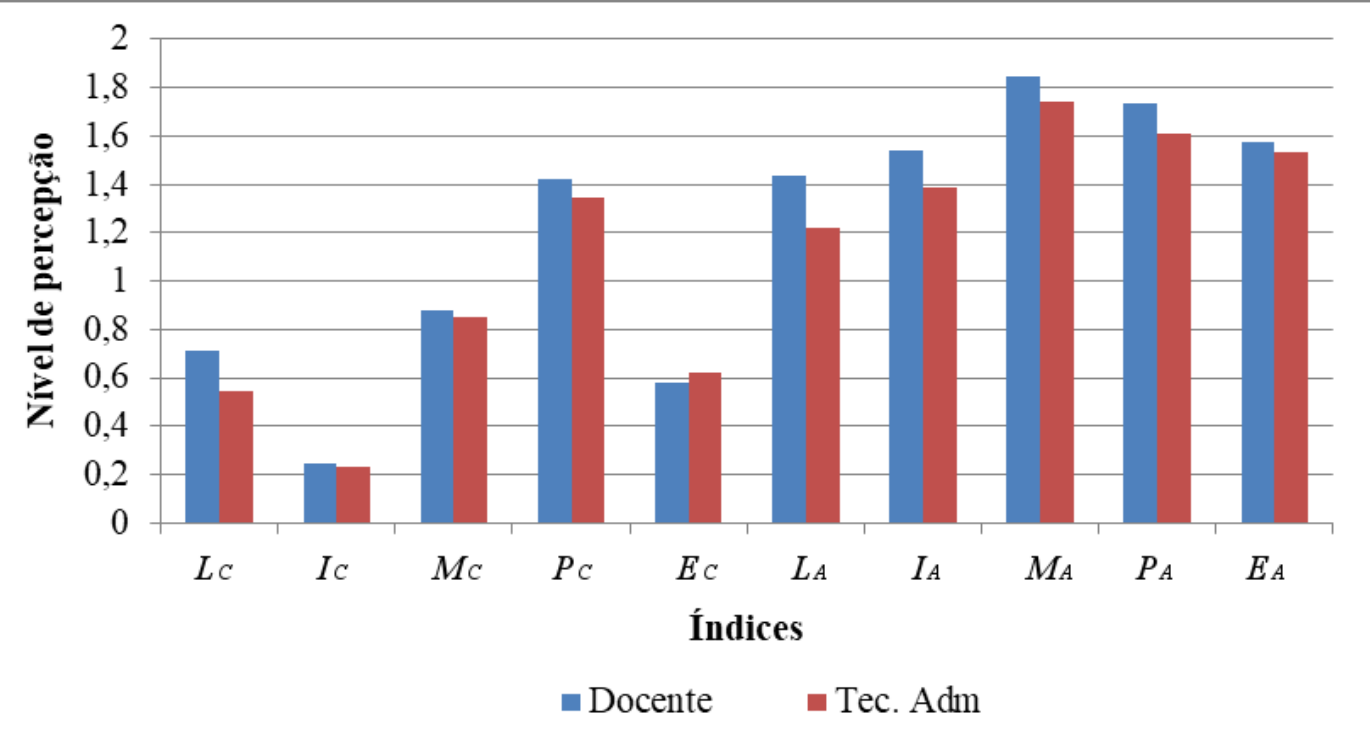

Fonte: dados da pesquisa 
A referida figura revela que os servidores do cargo de Docente possuem uma autopercepção acerca da prática dos princípios LIMPE em média maior em comparação com os Técnico-Administrativos em Educação. A diferença média dos índices é de 0,127. Pode-se imaginar que as razões que explicam tal fato sejam as diferenças do processo de formação, da seleção e das atividades desempenhadas por cada profissional. Para o técnico, o concurso público exige, além da formação necessária, conhecimentos prévios sobre Direito Constitucional e Administrativo. Além disso, estes lidam diariamente com processos administrativos que seguem as exigências impostas pela legislação. Para o docente, o concurso exige formação mais específica e a seleção não abrange temas do Direito, salvo aqueles que concorrem a vagas para professor de cursos da área do Direito. O docente também lida com processos administrativos, porém, em menor quantidade caso ele não exerça uma função de gestão.

Com relação à percepção sobre a prática dos princípios LIMPE no ambiente de trabalho, os Docentes possuem índices discretamente maiores em $L_{c}$, lc $M_{c}$ e $P_{c}$. Apenas no índice que avalia a eficiência no ambiente de trabalho é que os técnicos possuem uma média discretamente maior que os docentes. $O$ fato de os processos administrativos serem, em grande parte, tratados por técnicos pode justificar uma visão mais crítica de docentes que dependem, em certos casos, da eficiência dos técnicos.

A figura 5 mostra a percepção sobre a prática dos princípios de acordo com o exercício de função de gestão na Instituição.

Figura 5. Percepção dos entrevistados de acordo com o exercício de função de gestão

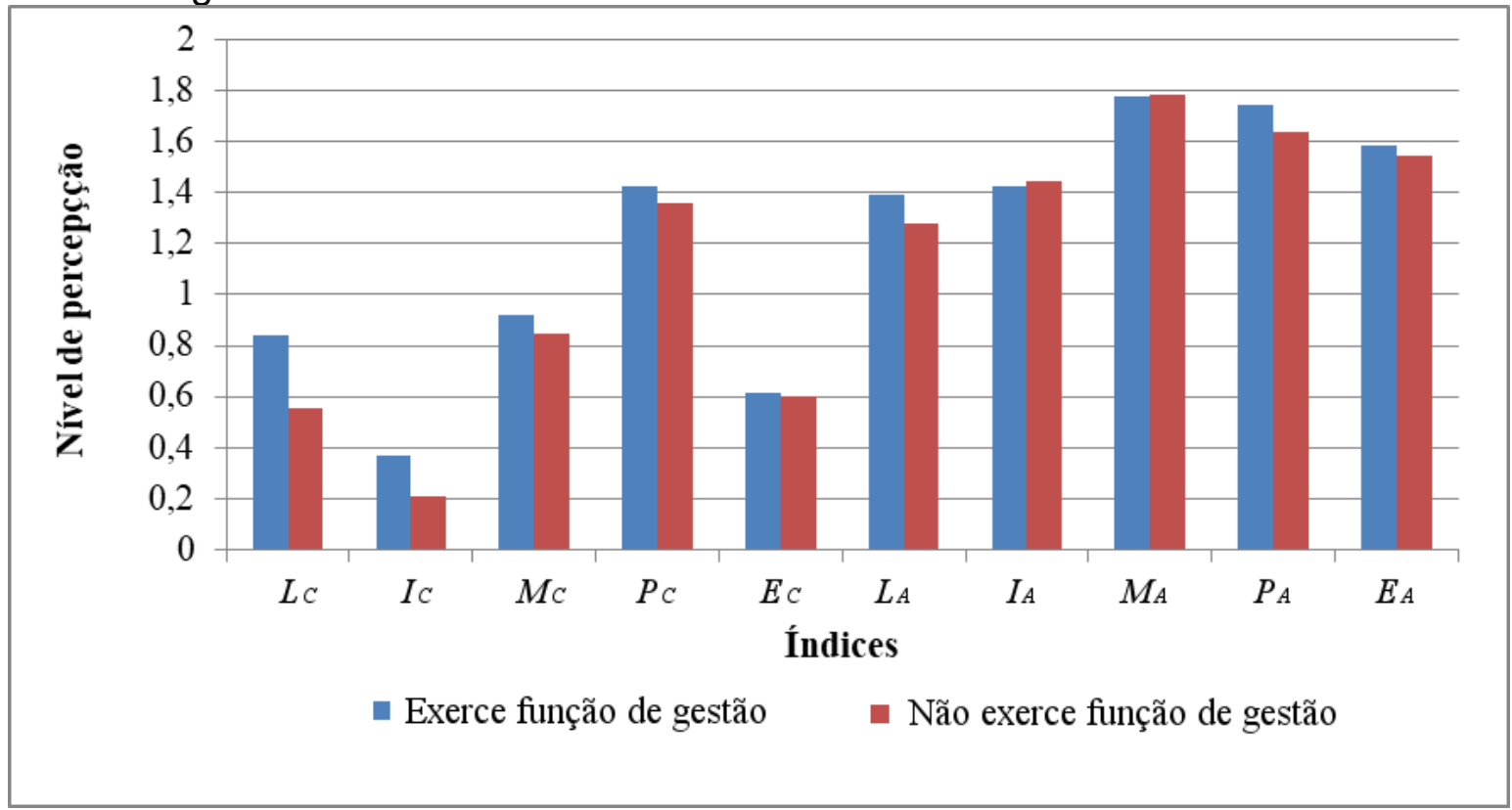

Fonte: dados da pesquisa

Observa-se na aludida figura que os servidores que exercem função de gestão têm uma percepção sobre a prática dos princípios LIMPE no ambiente de trabalho um pouco maior em comparação com os que não exercem. Isso pode ser reflexo da visão macro que esse profissional tem sobre os demais servidores, onde os atos praticados por um subordinado que não estejam de acordo com os princípios constitucionais da 
Administração Pública podem ensejar a responsabilização não só daquele que deu origem ao ato, mas também dos seus superiores.

No tocante à autopercepção, os servidores que exercem função de gestão possuem os índices $L_{A}, P_{A}$ e $E_{A}$ com médias discretamente maiores que aqueles que não exercem. Os índices $I_{A}$ e $M_{A}$ possuem médias similares para ambos tipos de servidores.

Os resultados expressam uma percepção positiva dos servidores da Universidade de Brasília sobre o cumprimento dos princípios constitucionais da Administração Pública contidos no artigo 37, caput, da Constituição Federal. As médias de autopercepção sobre a prática de determinado princípio é sempre maior que a percepção sobre o ambiente de trabalho em todas as análises efetuadas entre os índices, independentemente de características sociais ou profissionais. A idade e o tempo trabalhado na Universidade aparentemente não influenciam a percepção sobre a prática dos princípios. Já o gênero do servidor, o cargo exercido e o fato de atuar em uma função de gestão são características que podem interferir nos resultados. Destaca-se a existência de um número reduzido de servidores que não percebem a aplicação dos princípios nem nos atos dos colegas de trabalho e nem nos próprios atos. Nesses casos está presente a inobservância dos princípios constitucionais da Administração Pública, denotando, segundo Bandeira de Mello (2013) e Meirelles (2016) a insubordinação de valores fundamentais e a desconsideração da boa guarda e zelo de interesses sociais.

\section{CONCLUSÕES}

Este artigo objetivou buscar evidências sobre a percepção de servidores públicos a respeito da prática dos princípios constitucionais da Administração Pública explícitos no artigo 37, caput, da Constituição Federal. Para isso, foram construídos índices e indicadores para identificar tanto a autopercepção do servidor quanto a percepção dele com relação ao ambiente de trabalho sobre o cumprimento desses princípios. Posteriormente, foi realizada uma análise dos achados a partir das características pessoais e profissionais dos servidores. O estudo foi realizado na Universidade de Brasília.

Os resultados revelaram que a prática dos princípios LIMPE no ambiente de trabalho é percebida de maneira positiva. Entretanto, uma parcela de servidores não percebe o cumprimento de alguns dos princípios no ambiente de trabalho, principalmente o da impessoalidade. Já a autopercepção sobre a prática dos princípios é muito superior à percepção que o servidor possui sobre o ambiente de trabalho. A idade do servidor e o tempo de trabalhado na Instituição parecem não interferir na percepção sobre o cumprimento dos princípios LIMPE.

As mulheres, os docentes e os servidores que ocupam função de gestão possuem, na maioria das vezes, médias superiores sobre a percepção da prática dos princípios LIMPE em comparação com os homens, os técnico-administrativos em educação e os servidores que não exercem função de gestão, respectivamente.

É importante ressaltar as limitações deste trabalho. Primeiramente, deve-se registrar que houve significativo número de recusas de servidores a responder o questionário de pesquisa. Apesar de o questionário não armazenar informações que possibilitassem a identificação do servidor, alguns destes temiam que alguma retaliação fosse aplicada. 
Outra limitação é o fato de que a sensação de percepção declarada pelo servidor no momento em que este responde o questionário, pode ser afetada por diversas condições, entre elas é possível citar conflitos no ambiente de trabalho e dificuldades de autoavaliação.

A continuidade desta pesquisa apresenta os seguintes desafios: 1) a utilização de métodos estatísticos mais robustos para identificação de possíveis correlações entre os índices e indicadores e as características pessoais dos entrevistados; 2) a análise de diferenças de percepção entre os servidores que possuem e os que não possuem conhecimento sobre a legislação pertinente acerca do dever de probidade administrativa.

Sugere-se a aplicação deste experimento em outras instituições públicas, com vistas a compreender onde existe maior ou menor percepção sobre a prática dos princípios LIMPE. Trabalhos futuros também podem avaliar a percepção sobre a prática dos princípios implícitos na Constituição e nas normas infraconstitucionais.

Os resultados deste trabalho podem contribuir com uma autocrítica institucional, tendo em vista uma possível sobreavaliação dos servidores ao avaliarem a si próprios. Além disso, existem casos em que há a percepção de não cumprimento de princípios, apesar de a maioria dos servidores afirmarem que tanto os próprios atos quanto os atos realizados no ambiente de trabalho estão de acordo com os princípios LIMPE.

A partir dos resultados deste trabalho sugere-se que a Administração Pública adote medidas que aperfeiçoem a observância de tais princípios, de forma que todos os agentes públicos os cumpram e percebam a aplicação deles no ambiente de trabalho.

\section{REFERÊNCIAS}

AITH, F. Reflexões sobre o princípio da legalidade na ciência do direito contemporâneo. Revista de Direito Sanitário, São Paulo, v.5, n.3, p. 41-81, nov. 2004. Disponível em: http://www.revistas.usp.br/rdisan/article/view/79837. Acesso em: 5 fev. 2019

ALEXY, R. Teoria dos direitos fundamentais. Tradução: Virgílio Afonso da Silva. São Paulo: Malheiros, 2008.

BANDEIRA DE MELLO, C. A. Curso de direito administrativo. 30.ed. rev. e atual. São Paulo: Malheiros, 2013.

BARROSO, L. R.; BARCELLOS, A. P. O começo da história. A nova interpretação constitucional e o papel dos princípios no direito brasileiro. Revista de Direito

Administrativo, Rio de Janeiro, v. 232, p. 141-176, abr. 2003. Disponível em: <http://bibliotecadigital.fgv.br/ojs/index.php/rda/article/view/45690>. Acesso em: 22 Maio 2019.

BARROSO, L. R. Interpretação e aplicação da Constituição: fundamentos de uma dogmática constitucional transformadora. 7. ed. rev. São Paulo: Saraiva, 2009.

BONAVIDES, P.; MIRANDA, J.; AGRA, W. M. (coord.). Comentários à

Constituição Federal de 1988. Rio de Janeiro: Forense, 2009. 
BRASIL. [Constituição (1988)]. Constituição da República Federativa do Brasil de 1988. Brasília, DF: Presidência da República, [2018]. Disponível em:

http://www.planalto.gov.br/ccivil_03/constituicao/constituicaocompilado.htm. Acesso em: 4 jan. 2019.

BRASIL. Lei 12.527, de 18 de novembro de 2011. Lei de Acesso à Informação. Brasília, DF: Presidência da República, [2011]. Disponível em:

http://www.planalto.gov.br/ccivil_03/_ato2011-2014/2011/lei/l12527.htm. Acesso em: 20 fev. 2019.

BRASIL. Lei 3.998, de 15 de dezembro de 1961. Autoriza o Poder Executivo a instituir a Fundação Universidade de Brasília, e dá outras providências. Brasília, DF: Presidência da República [1961]. Disponível em: http://www.planalto.gov.br/ccivil_03/ LEIS/1950-1969/L3998.htm. Acesso em: 22 fev. 2019.

BRASIL, Lei no 8.112, de 11 de dezembro de 1990. Dispõe sobre o regime jurídico dos servidores públicos civis da União, das autarquias e das fundações públicas federais. Brasília, DF: Presidência da República [1990]. Disponível em http://www.planalto.gov.br/ccivil_03/LEIS/L8112cons.htm. Acesso em: 4 fev. 2019.

BRASIL. Lei no 9.784, de 29 de janeiro de 1999. Regula o processo administrativo no âmbito da Administração Pública Federal. Brasília, DF: Presidência da República [1999]. Disponível em http://www.planalto.gov.br/ccivil_03/LEIS/L9784.htm. Acesso em: 5 fev. 2019.

CANOTILHO, J. J. Direito constitucional e teoria da constituição. 7. ed. Coimbra: Almedina, 2003.

CARVALHO FILHO, J. S. Manual de direito administrativo. 32. ed. São Paulo: Atlas, 2018.

DI PIETRO, M. S. Z. Direito Administrativo. 31. ed. rev. atual e ampl. Rio de Janeiro: Forense, 2018.

FAZZIO JÚNIOR, W. Improbidade administrativa: doutrina, legislação e jurisprudência. 4. ed. rev., atual. e ampl. São Paulo: Atlas, 2016.

GUNTER, K. Teoria da argumentação no direito e na moral: justificação e aplicação. Tradução Cláudio Molz. São Paulo: Landy, 2004.

HAURIOU, M. Précis élementaires de droit administraif. 2. ed. Paris: [S.I.], 1926.

HESSE, K. A força normativa da constituição. Tradução de Gilmar Ferreira Mendes. Porto Alegre: Sérgio Antônio Fabris Editor, 1991.

LIKERT, R. A technique for the measurement of attitudes. Archives of Psychology. Nova lorque, v. 22, n. 140, p. 5-55, 1932. Disponível em: https://legacy.voteview.com/pdf/Likert_1932.pdf. Acesso em: 06 mar. 2019.

LIMA, E. C.; OLIVEIRA, F. E. A.; NETO, J. C. C. O princípio da impessoalidade da administração pública: uma análise de sua aplicabilidade ao longo do tempo.

Revista Científica do ITPAC, Palmas, v. 3, n. 1, p. 12-15. jan. 2010. Disponível em: https://assets.itpac.br/arquivos/Revista/31/2.pdf. Acesso em: 11 fev. 2019. 
MARRARA, T. As fontes do direito administrativo e o princípio da legalidade.

Revista Digital de Direito Administrativo, São Paulo, v. 1, n. 1, p. 23-51, 2014. Disponível em: http://www.revistas.usp.br/rdda/article/view/73561. Acesso em: 08 fev. 2019.

MARTINS, M. P. Os princípios e a normatividade jurídica. In: Série Aperfeiçoamento de Magistrados, 11, 2012, Rio de Janeiro. Normatividade Jurídica. Rio de Janeiro: EMERJ, 2013. p. 197-207. Disponível em:

http://www.emerj.tjrj.jus.br/serieaperfeicoamentodemagistrados/paginas/series/11/nor matividadejuridica_expediente.pdf. Acesso em: 21 mai. 2019.

MEDAUAR, O. Direito administrativo moderno. 21.ed. Belo Horizonte: Fórum, 2018.

MEIRELLES, H. L. Direito administrativo brasileiro. 42.ed. atual. São Paulo: Malheiros, 2016.

MOREIRA NETO, D. F. Curso de direito administrativo: parte introdutória, parte geral e parte especial. 16.ed. rev. e atual. Rio de Janeiro: Forense, 2014.

MUNIZ, C. C. B. O princípio da eficiência na administração pública brasileira. Prisma Jurídico, São Paulo, v. 6, p. 85-100, 2007. Disponível em

http://periodicos.uninove.br/index.php?journal=prisma\&page=article\&op=view\&path\% 5B\%5D=1130. Acesso em: 20 fev. 2019.

SILVA, J. A. Curso de direito constitucional positivo. 25. ed. rev. e at. São Paulo: Malheiros, 2005.

SOUSA, F. O. O raciocínio jurídico entre princípios e regras. Revista de informação legislativa, Brasília, v. 48, n. 192, p. 95-109, out./dez. 2011. Disponível em https://www2.senado.leg.br/bdsf/item/id/242932. Acesso em 24 jun. 2019.

UNIVERSIDADE DE BRASÍLIA (UNB). Coordenadoria de Estudos em Gestão de Pessoas - CODE. Relação dos docentes e técnicos administrativos da UnB. Brasília: Universidade de Brasília, 24 jun. 2019. Disponível em: http://www.dgp.unb.br/dados-abertos\#relacao-dos-tecnicos-administrativos-da-unb. Acesso em: 9 jul. 2019.

UNIVERSIDADE DE BRASÍLIA (UNB). Estatuto e Regimento Geral. 8.ed. Brasília: Editora UnB, 2011. 
9. Apêndice - Questionário

SEÇÃO 1 - O seguinte questionário deve ser respondido tendo por base as atitudes percebidas por você diante da atuação dos seus colegas de trabalho nas diversas atividades realizadas no âmbito da Administração Pública.

Q1. Em seu ambiente de trabalho a lei norteia as decisões tomadas, pois nesse ambiente não há vontade pessoal.
( ) Nunca acontece( ) Quase nunca acontece vezes não
( ) Quase sempre acontece
( ) Sempre acontece

Q2. O estatuto e o regimento da Universidade são documentos observados a fim de amparar decisões no ambiente de trabalho.
( ) Nunca acontece( ) Quase nunca acontece
( ) Às vezes acontece, outras vezes não
( ) Quase sempre acontece
( ) Sempre acontece

Q3. Em decisões tomadas no ambiente de trabalho, as razões pessoais dos servidores não prevalecem sobre o interesse público.
( ) Nunca acontece( ) Quase nunca acontece
( ) Às vezes acontece, outras vezes não
( ) Quase sempre acontece
( ) Sempre acontece

Q4. Em reuniões das quais eu participo, interferências políticas ou ideológicas não prevalecem sobre o interesse da coletividade.
( ) Nunca acontece( ) Quase nunca acontece
( ) Às vezes acontece, outras vezes não
( ) Quase sempre acontece
( ) Sempre acontece

Q5. A atuação dos meus colegas de trabalho na Universidade é pautada por padrões éticos de probidade, decoro e boa-fé.

( ) Nunca acontece ( ) Quase nunca acontece ( ) Às vezes acontece, outras vezes não
( ) Quase sempre acontece
( ) Sempre acontece

Q6. As decisões tomadas, mesmo estando de acordo com as normas, não ofendem a moral, os bons costumes, as regras de boa administração, os princípios de justiça e de equidade e a ideia comum de honestidade.
( ) Nunca acontece( ) Quase nunca acontece
( ) Às vezes acontece, outras vezes não
( ) Quase sempre acontece ( ) Sempre acontece 
Q7. Quando solicitadas, as informações contidas nos atos administrativos são disponibilizadas pelos servidores, exceto nos casos de sigilo ou restrição prevista em lei.

( ) Nunca acontece ( ) Quase nunca acontece ( ) Às vezes acontece, outras vezes não
( ) Quase sempre acontece
( ) Sempre acontece

Q8. Chamamentos públicos (por exemplo: editais) são divulgados pelos seus responsáveis nos meios que permitam o acesso pelos interessados.
( ) Nunca acontece( ) Quase nunca acontece
( ) Às vezes acontece, outras vezes não
( ) Quase sempre acontece
( ) Sempre acontece

Q9. Os servidores cumprem os objetivos da Instituição utilizando metodologias e ferramentas apropriadas, sempre observando a otimização dos gastos públicos.
( ) Nunca acontece( ) Quase nunca acontece
( ) Às vezes acontece, outras vezes não
( ) Quase sempre acontece
( ) Sempre acontece

Q10. Os servidores realizam as atribuições do cargo com presteza, perfeição e rendimento.
( ) Nunca acontece( ) Quase nunca acontece
( ) Às vezes acontece, outras vezes não
( ) Quase sempre acontece
( ) Sempre acontece

SEÇÃO 2 - O seguinte questionário deve ser respondido tendo por base as suas atitudes no ambiente de trabalho. Deve-se levar em consideração toda e qualquer atividade realizada no âmbito da Administração Pública.

Q1. No ambiente de trabalho a lei norteia as minhas decisões, pois nesse ambiente não há vontade pessoal.
( ) Nunca acontece( ) Quase nunca acontece vezes não
( ) Quase sempre acontece
( ) Sempre acontece

Q2. O estatuto e o regimento da Universidade são documentos observados por mim a fim de amparar decisões no ambiente de trabalho.
( ) Nunca acontece( ) Quase nunca acontece
( ) Às vezes acontece, outras vezes não
( ) Quase sempre acontece
( ) Sempre acontece 
Q3. Em decisões tomadas no ambiente de trabalho, as minhas razões pessoais não prevalecem sobre o interesse público.
( ) Nunca acontece( ) Quase nunca acontece vezes não
( ) Quase sempre acontece
( ) Sempre acontece
( ) Às vezes acontece, outras
Q4. Nas decisões tomadas por mim no ambiente de trabalho, o interesse público se sobrepõe a qualquer interferência política ou ideológica.

( ) Nunca acontece( ) Quase nunca acontece ( ) Às vezes acontece, outras vezes não
( ) Quase sempre acontece
( ) Sempre acontece

Q5. A minha atuação na Universidade é pautada por padrões éticos de probidade, decoro e boa-fé.
( ) Nunca acontece( ) Quase nunca acontece vezes não
( ) Quase sempre acontece
( ) Sempre acontece
( ) Às vezes acontece, outras

Q6. As minhas decisões, mesmo estando de acordo com as normas, não ofendem a moral, os bons costumes, as regras de boa administração, os princípios de justiça e de equidade e a ideia comum de honestidade.
( ) Nunca acontece( ) Quase nunca acontece
( ) Às vezes acontece, outras vezes não
( ) Quase sempre acontece
( ) Sempre acontece

Q7. As informações contidas nos atos administrativos confeccionados por mim são disponibilizadas para o público, exceto nos casos de sigilo ou restrição prevista em lei.
( ) Nunca acontece( ) Quase nunca acontece vezes não
( ) Quase sempre acontece
( ) Sempre acontece
( ) Às vezes acontece, outras

Q8. Ao tratar de chamamentos públicos (por exemplo: editais), realizo a divulgação em meios que permitam o acesso pelos interessados.
( ) Nunca acontece( ) Quase nunca acontece
( ) Às vezes acontece, outras vezes não
( ) Quase sempre acontece
( ) Sempre acontece

Q9. Cumpro os objetivos da Instituição utilizando metodologias e ferramentas apropriadas, observando a otimização dos gastos públicos.
( ) Nunca acontece( ) Quase nunca acontece
( ) Às vezes acontece, outras vezes não
( ) Quase sempre acontece
( ) Sempre acontece 
Q10. Realizo as atribuições do cargo com presteza, perfeição e rendimento.

( ) Nunca acontece( ) Quase nunca acontece ( ) Às vezes acontece, outras vezes não
( ) Quase sempre acontece
( ) Sempre acontece

SEÇÃO 3 - Informações sociais e profissionais:

1. Em que ano você nasceu?

2. Em que ano começou a trabalhar na UnB?

3. Sexo: ( ) Feminino ( ) Masculino

4. Qual o seu cargo na UnB?

( ) Técnico-Administrativo ( ) Docente ( ) Não possuo vínculo com a UnB

5. Exerce alguma função de direção ou coordenação?
( ) Não
( ) Sim, de coordenador ( ) Sim, de diretor ( ) Sim, de decano

( ) Sim, outro:

6. Conhece a legislação pertinente acerca do dever de probidade administrativa.

( ) $\operatorname{Sim}($ ) Não 